\title{
MACHINERY AND LABOR
}

\section{By Henry White}

\author{
General Secretary, United Garment Workers of America
}

This subject is one which involves the whole industrial problem. It is the complexity of conditions due to the introduction of machinery which has caused the wide differences of opinion upon the question of wealth distribution. Under the simpler methods of industry the manner in which the proceeds of labor were divided was readily understood; to-day, however, the system is so highly organized that there is much confusion as to its operations. The perplexity is so great that many who see in labor-saving inventions some malign purpose, and others again who discern that any means which enhances the productiveness of labor must benefit mankind, are unable to comprehend the manner by which that result is effected. The habit of judging the operations of so complex a system by the effect upon special interests instead of viewing it as a whole, accounts for the common misconception regarding the function of machinery.

If people were to consider how meagre would be the rewards of toil without the aid of machinery, how costly the necessities of life, and how small the purchasing power of the laborer, its uses would soon become apparent. The confusion is heightened by the dual relation which a person occupies as a producer and as a consumer. As a consumer he benefits almost at once by every saving in effort, while as a producer his means of a livelihood may in consequence be threatened. The laborers thrown out of work by a machine or even the merchant forced out of business through some combination cannot be expected to appreciate the beneficence of such economy. In both cases their horizon is limited to their own means of a livelihood. When a person finds his occupation suddenly gone, it outweighs all other considerations; and unmindful of the benefits he may have received from similar economies in other trades, inventions to him seem a curse. The rewards of the particular invention which distresses him go to the body of consumers and he only shares indirectly as one of them. In the case of the wage-workers the gain is not evident as it is with the manufacturer 
who first utilizes an invention, and consequently their views on the subject will differ correspondingly. It is regrettable that even the temporary disadvantages of industrial progress should fall heavily upon some to the advantage of others, but it is as unavoidable as friction is to motion. The suffering can be mitigated only in proportion as our knowledge of the methods of industry increases, by recognizing the inevitableness of the changes and preparing to meet them.

Economic laws, like the laws of nature, admit of no exceptions. Were discriminations possible the consequences would make the present hardships seem nothing in comparison. In fact, society would quickly disintegrate and revert to its primitive state. If society had to wait for the sanction of every person before a forward step could be taken it would never start. In the process of adjustment and readjustment which progress implies, it is unavoidable that some have to be forced out of old grooves and made to fit into new ones. It is this adaptability to change which characterizes modern enterprise; this willingness to suffer immediate discomforts for the achievement of larger ends.

The general confusion as to the service rendered by machinery is not strange considering the absurd notions which are rife regarding the rudiments of social economy. No distinction is usually made between useful and useless labor. There is supposed to be only a given amount of work to be done, and hence the less each one does the more jobs there will be to go around. If wealth be wasted or destroyed, it will in some mysterious manner be replaced. The destruction of property by fire or flood is regarded with complacency by those not directly affected, upon the supposition that more work is thereby provided, without taking into account that the wealth required to replace it must be diverted from some productive use. The spending or circulating of money is equivalent to creating wealth. Luxury is looked upon with more favor than frugality, and it is even thought that gambling benefits a community as much as industry because the fortunate ones spend freely, and the misery which it begets is lost sight of in contemplation of the profits of a few. With such erroneous ideas entertained even by educated people, it is apparent why the complex operations of our industrial system are so slightly understood. The expansion of industry which follows labor-saving devices, the creation of new industries and the consequent replacing of those displaced is un- 
intelligible to all save those that comprehend economic principles. In addition to the popular misconceptions of the subject, there are historic causes which have created this antipathy to machinery. During the transition from the domestic to the factory system in England, machinery became a club to subjugate the laborer. Untutored, unorganized, without any resisting power, the former independent artisan. now a factory hand, was placed in brutal competition with his fellows, and every invention only served to add to his helplessness. The plight of the English laborers at that time abundantly shows that there are circumstances in which the wealth of a nation may increase tremendously, the productive power of labor multiply many-fold, while the workers on the other hand become impoverished and brutalized. Mill was of the opinion that machinery had not benefited the working class, but happily, since the time in which he wrote, education and organization, two indispensable factors in their advancement, have come to their aid. An upward trend has in consequence taken place, and the stimulus which it has given will make a relapse, owing to the advances in sanitary science, as improbable as another visitation of a plague. Where the workers have succeeded in acquiring some independence, in raising their standard of living, machinery, despite the drawbacks described, has undoubtedly become a potent factor in the elevation of their class.

Under a collective system the immediate benefits which would be derived by each individual through labor-saving inventions are its chief merit, but to compare the good features of an imaginary social system with the disadvantages of the existing one is not an easy task. It can, however, be shown that this desired co-operative principle actually does work out at the present time in a rough way by the distribution of the benefits of inventions throughout society and that there are possibilities for a more perfect application of it.

As to the workers' share in production, Karl Marx in his incisive analysis comes to the conclusion that the value of commodities is based upon the labor cost plus the profits of the capitalist and in that he is in accord with the authorities upon social science since Adam Smith. He deduces from that, that labor alone represents the actual wealth which is exploited for profit by the capitalist and that the very capital invested was previously appropriated from the laborer. Granting this conclusion, Marx should have 
made allowance for the competition between capitalists by which the price of commodities is kept within certain limits and the benefits of cheaper production are given to the consumers. In the cases Marx deals with, cheaper production unfortunately did not only mean more economical methods, but lower wages and long hours and the sacrifice of the worker, while the consumer represented some one else than the operative, who barely subsisted on his pittance. Without the ability to purchase the goods he produced, England had to dispose of in foreign markets that which should have been consumed at home, always the best market. Her chief dependence being upon outside markets, everything had to be subordinated to cheaper production, no matter how obtained.

Concerning the attitude of trades unions upon the question of machinery, the membership being composed of men with the usual abilities, their views do not materially differ from others. Having, however, the benefits of an education derived from a close study of economic problems and an experience which has helped them form broader opinions, they are gradually reconciling themselves to machinery. As for example the action taken at the late convention of the American Federation of Labor held at Scranton. In a resolution introduced by the delegates of the Cigar Makers' International Union requesting that a certain firm be declared unfair, there was reference to a cigar-making machine used in the shop of this employer. Although the machine was mentioned as an evidence only of the inferiority of the product of the concern, a vigorous objection was at once raised by the delegates against any mention of the use of machinery by the firm. In the debate which followed, it was argued that the convention could not afford to go on record as against labor-saving devices and that any attempt to oppose them would prove futile. The objectionable words were stricken out by a decisive vote. As to what action the convention would have taken if the delegates had thought it possible to suppress the machine is a question. The decision of the convention, however, has brought the movement to a point in which the members will be enabled to take a more liberal and complete view of the subject, and realize that the limitation of work is not only impolitic, but that by increasing their capacities the opportunity is afforded for them to insist upon a fair share in the larger prodduct. The British unions have not advanced in that respect as far as the American unions because the habits of the working 
people there are more set, but circumstances have also changed very much their attitude toward machinery.

The Typographical Union is a notable example of a union which accepted a revolutionizing invention as being inevitable, and thus succeeded in securing a rate of wages for the operators considerably in excess of that received by the hand compositors. An officer of the New York Union estimates that each linotype machine introduced into the newspaper offices displaced three men, and that within three years, owing to the increase in the size of the newspapers and the larger demand for printed matter which it encouraged, the men laid off have been re-employed, and that to-day the pay-rolls even exceed the former figure. This machine has also had the effect of elevating the standards of the craft, owing to the higher skill and education required. The competition among the employers is such that profits are reduced to a minimum, the public therefore receiving the full benefit of the improvement.

In the building trades, similar results are also noted. Improved methods have led to a prodigious expansion in building operations. The laborer's work is now largely done by mechanical means, and parts of a structure, such as the trimmings, are made in factories and are only fitted together upon the premises. The subdividing of the work is carried on to an extent that a number of contractors, each performing a distinct function, co-operate in the completion of a single building. When this specializing began and the ingenious hod-hoisting device made it unnecessary for men to make beasts of burden of themselves, a general alarm was created over the prospect of great numbers of workmen being thrown out of employment. To-day a far greater number of men are steadily employed in this fundamental industry than at any time in its. history.

Examples of this kind can be cited indefinitely to demonstrate the larger results which flow from greater economy in effort. Allowances are seldom made for the enterprises which could not be carried on at all were it not for labor-saving methods.

The lowering of the cost of commodities enables the average person to indulge in what were formerly considered luxuries, and by this encourages the development of new industries. The tendency under the influence of machinery is for industry to spread out fan-shape, ever widening as the distance from the starting point increases. Were it not for the limitations set by the pur- 
chasing capacity of the people and the periodical disarrangements or panics which occur as a result of what is conveniently termed over-production, there would be no check. To fear a surfeit of wealth seems absurd considering the needs of the average person. What is meant by over-production is the inability to buy what has been produced.

Russia with her immense population is unable to consume the products of her few mills, while in the United States, where the efficiency of labor is higher than anywhere else and is being increased at a marvelous rate, not to speak of the half-million aliens absorbed every year, the percentage of unemployed is lower than it has been for years, and even less than during the earlier part of our history when manufacturing was in its infancy.

To increase the purchasing capacity of the people either by higher wages or cheaper products is to reduce the surplus and maintain an equilibrium, hence the economic value of higher standards of living. Production cannot be greater than the ability of the average person to consume, any more than water can rise higher than its source, therefore increased production must be accompanied by the same increase in consumption, if normal conditions are to be maintained. No matter to what extent machinery, division of labor or economy in management may be perfected theoretically, the demand for labor ought not to be diminished. The eight-hour work is advocated by many, not because of the personal benefit to the workman, but upon the same grounds that they would favor the curtailment of production, in the belief that it would increase the number of the employed. By decreasing the average amount of work done in order that it may be distributed more evenly may accomplish that object temporarily, but if generally practiced would decrease the demand for work through the increase of the price of the commodity.

It is doubtful if workmen in a particular craft have ever succeeded for a length of time in erecting a wall around themselves and preventing as many extra men as could be employed from getting in if the emoluments were sufficient. So even if it were possible to so restrict work as to create a scarcity of workmen, this pressure from without would prove irresistible and the normal level would be maintained. If on the contrary a lack of work would make a number of workmen superfluous, there would be a tendency for them to find their way into growing occupations. Union 
regulations, such as apprenticeship rules, can and do prevent undue crowding into a trade owing to a sudden and temporary demand which would prove highly injurious unless checked, for it would serve to break down standards upheld by the union. Through such means an assimilation of those entering the trade is gradually accomplished.

Unions have been frequently charged with trying to restrict output. The same accusation has also with equal effect been made against industrial combinations for seeking to create an artificial scarcity. In many cases where unions endeavor to prevent rush or driving work injurious to the worker, they have been accused of limiting work. Such restrictions can be easily defended. That labor organizations have in some instances attempted to prevent the use of labor-saving appliances there can be no question considering the prevailing ideas on the subject, and organized workmen can give force to their opposition, but that such is the policy of labor movement is far from fact as I have just illustrated. The opposition to labor-saving methods is not confined to workmen alone, for employers will rail against competitors able to give better service for less cost. The same resentment at being forced out of a settled occupation is entertained by all.

The actual injury done by machinery is caused by the suddenness of the changes that result. Since there could be no way of regulating inventive genius, and the incentives for using improvements will remain as great, the rational and the only way to meet them is by preparation. The working class suffers most because it is less able to accommodate itself to new situations. The rising generation should be better equipped with a general knowledge of mechanics, and taught how to handle tools with skill. Such a training would undoubtedly relieve the difficulty and it could only be adequately supplied by the public schools. The results would be to increase the independence of workmen, as they would not then rely upon a small division of a trade or upon a single employer. Independence and higher wages go together. Unskilled laborers in some cases learn more than skilled mechanics for the reason that workmen trained only in one craft are usually unfitted for other work, while those accustomed to being thrown upon their own resources are more adaptable.

In the case of the aged workman the situation is specially hard, as he cannot find any place in an industrial system in which alert- 
ness counts for more than skill. He cannot profit by accumulated experiences as others do. It is the tragic side of the question, this grievous predicament of the worker who has spent his energies adding to the nation's wealth. It can and ought to be overcome, rot by any system of alms-giving which must always prove inadequate, not by retiring him to idleness, but by keeping him employed at such work as his long training and peculiar abilities fit him for. As his earning power declines at a certain period, some system of insurance could supply. the deficiency.

In respect to the material advantages of machinery, it surely has enlarged the capacities of the people and multiplied their opportunities. The possibilities are such as to make the mind tremble in anticipation. It is the agency which alone can raise wages, reduce the working time and enhance the buying power of money-a threefold gain.

The feeling against machinery will not cease until the workman profits more directly as a producer as well as a consumer, until he is treated as a human being and not as a mere animated tool, until he becomes more than a tender, an incident in production. The human element must become more evident and the toiler made to feel his partnership. The true mission of machinery would then be revealed to all as the only means which liberate man from drudgery, increase his control over nature and provide the leisure essential to a higher culture.

One of the acknowledged evils of machinery is the exploitation of child labor which usually follows its introduction. Such was the case in England, and we find it repeated to-day in the new industrial districts of the South. In such industries where the repetition of a small mechanical process enables child labor to be employed, the temptation to take advantage of the opportunity is great; for children have no rights to assert, no wage scale to uphold or working time to protect. In that respect child labor is akin to slave labor. It must be added for fairness that the capitalists utilizing such opportunities are not alone to blame, for shortsighted and grasping parents often drive their children into the mills because of the paltry sum which can be added to the family income, and in time they get into the habit of depending upon the pittance purchased at so terrible a price.

The inducement of a "plentiful supply of cheap labor" is also held out to capitalists by small communities as a means of per- 
suading them to locate factories in their neighborhood. These are the two chief obstacles in the way of reform. In course of time, however, as the consequences become more evident and the exultation over the establishment of a new factory wears off, the public conscience revolts against this debasement of the helpless children and the law is eventually evoked to suppress the evil. The strenuous efforts being made in the South upon the part of the labor organizations and sympathizers to enact protective laws lead us to hope that we will at least be spared the dreadful experiences of England during the first half century of the factory system. 